\title{
THE FREQUENCY OF EGFR AND KRAS MUTATIONS IN THE TURKISH POPULATION WITH NON-SMALL CELL LUNG CANCER AND THEIR RESPONSE TO ERLOTINIB THERAPY
}

\author{
Demiray A ${ }^{1, \#}$, Yaren $\mathrm{A}^{2}$, Karagenç $\mathrm{N}^{1}$, Bir $\mathrm{F}^{3}$, Demiray $\mathrm{AG}^{2}$, \\ Karagür ER ${ }^{1}$, Tokgün $\mathrm{O}^{1}$, Elmas L ${ }^{1}$, Akça $\mathrm{H}^{1, *}$ \\ \#https://orcid.org/0000-0002-3343-0184. \\ *Corresponding Author: Professor Dr. Hakan Akça, Cancer Research Center, Pamukkale University, \\ 11 University Street, Denizli Turkey. E-mail: hakca@pau.edu.tr (primary),hakanakca@yahoo.com
}

\begin{abstract}
In this study, profiles of epidermal growth factor receptor (EGFR) and Kirsten ras sarcoma (KRAS) mutations and response to erlotinib therapy have been investigated in patients with non-small cell lung cancer (NSCLC). DNA from 300 patients with NSCLC was extracted from paraf-finembedded tissues. After the extracted DNA was sequenced by pyrosequencing method, a total of 97 (32.0\%) patients out of 300 were detected to carry an EGFR mutation and 75 $(25.0 \%)$ patients out of 300 carried a KRAS mutation; 20 (6.6\%) patients were detected to carry both of EGFR and KRAS mutations. The EGFR mutations were found to be statistically significant in female patients (48.0 women $v$ s. $28.0 \%$ men, non smokers (49.0 vs. $26.0 \%$ ) and adenocarcinoma (37.8 vs. squamous $26.8 \%$ ). The overall rate of survival in patients receiving erlotinib therapy than in patients who did not. In patients without the KRAS mutation, the median overall survival rate was $161 \pm 30$ weeks with erlotinib therapy and $90 \pm 13$ weeks in patients without erlotinib therapy. In patients having KRAS mutation, the median overall survival was $98 \pm 16$ weeks with erlotinib therapy and $34 \pm 16$ weeks with no erlotinib therapy. In our study, we once again demonstrated that the presence of these mutations affected response to erlotinib therapy. The KRAS mutations negatively affected survival rate with and without erlotinib therapy.

Keywords: Erlotinib therapy; Epidermal growth factor receptor (EGFR); Kirsten ras sarcoma (KRAS); Non-small cell lung cancer (NSCLC).

\footnotetext{
${ }^{1}$ Medical Biology Department, Pamukkale University, Denizli, Turkey

${ }^{2}$ Medical Oncology Department, Pamukkale University, Denizli, Turkey

${ }^{3}$ Medical Pathology Department, Pamukkale University School of Medicine, Denizli, Turkey
}

\section{INTRODUCTION}

Lung cancer is one of the main leading causes of cancer death, and the most common cancer after prostate and breast cancers, in respect to prevalence [1]. The 5-year overall survival is $15.0 \%$ in patients with non-small cell lung cancer (NSCLC) [1]. Overall survival rates increase with surgical, chemotherapy and radiotherapy treatments in early stages of the cancer [2]. Recently, immunotherapy and molecular targeted therapy have been used to treat cancer patients. Erlotinib and gefitinib, which are the inhibitors of epidermal growth factor receptor (EGFR) tyrosine kinases are molecular targeted agents. These agents have been used to inhibit certain EGFR tyrosine kinase mutations. Both of them can pass through the phospholipid membrane into the cell, and these agents compete with adenosine triphosphate (ATP) to bind the ATP binding pocket of EGFR. The EGFR, a transmembrane glycoprotein of $170 \mathrm{kDa}$ consisting 1186 amino acids, is localized in the 7q12 chromosome region. It is known that the EGFR receptor has mutations in the tyrosine kinase region of 18-21 exons in NSCLC cells and correlate therapy response. These EGFR mutations are more common in Asian, Caucasian and non smoking women [4]. K-ras, a downstream protein, becomes constantly active as a result of EGFR auto-phosphorylation. The Kirsten ras sarcoma (KRAS) gene belongs to Ras gene family and homolog of Kristen rat sarcoma viral oncogene [5-8]. It is localized at the chromosome 12 (12q12.1) region and consists of six exons transcribed as a small guanosine triphosphatease (GTPase) consists of $21 \mathrm{k} \mathrm{Da}$ and 189 amino acids [5,7]. Codons 12 and 13 have GTPase-acting proteins (GTPs) binding site in the KRAS gene. Codon 61 is the switch II region that regulates Ras protein. Mutations at codons 12, 13 and 61 prevent GTP hydrolysis causing K-ras protein constantly active situation. Studies have shown that NSCLC patients 
with KRAS mutations have lower survival rates than those without KRAS mutations [6].

In our study, we investigated the frequency of EGFR and KRAS mutations and effects of anti-EGFR tyrosine kinase inhibitors treatment in Turkish NSCLC patients. This is the first large-scale study that investigates EGFR and KRAS mutations in 300 patients with NSCLC in Turkey.

\section{MATERIALS AND METHODS}

Patients. This study was performed in paraffin-embedded tissues of 300 NSCLC patients who attended the Medical Oncology Department, Pamukkale University, Denizli, Turkey, Medical Oncology Department, Antalya Education Research Hospital, Antalya, Turkey and the Medical Oncology Department, Afyon Kocatepe University, Afyon, Turkey, between 2011 and 2014. DNA was extracted from paraffin-embedded tissues using QIamp DNA FFPE Tissue kit (Qiagen GmbH, Hilden, Germany, its purity was checked spectrophotometrically and stored at $-20{ }^{\circ} \mathrm{C}$. Clinical features of patients are given in Table 1 .

Pyrosequencing Method. The extracted DNA was sequenced by pyrosequencing, a method which gives effective with as little as $15 \mathrm{ng}$ DNA. This method is based on a real time non electrophoretic system. Pyrosequencing is more cost-effective when compared to the dideoxy Sanger method. Pyrosequencing is more reliable and effective at determining EGFR mutations than the classic sequencing method [9]. Polymerase chain reaction (PCR) reaction composed of $20 \mathrm{pmol}$ of each primer, $0.2 \mathrm{mmol}$ each of deoxy-nucleotide triphosphates, $1.5 \mathrm{mmol} / \mathrm{L} \mathrm{MgCl} 2$ and 1.25 U of FastStart Taq DNA polymerase (Qiagen GmbH)
Table 1. Clinicopathological characteristics of the patients.

\begin{tabular}{|l|c|}
\hline Characteristics & Patients $(\boldsymbol{n}=\mathbf{3 0 0}) \mathbf{( \% )}$ \\
\hline $\begin{array}{l}\text { Age: } \\
\quad \leq 62 \text { years }\end{array}$ & $148(49.3)$ \\
$\quad \geq 62$ years & $152(50.7)$ \\
\hline $\begin{array}{l}\text { Gender: } \\
\text { males } \\
\text { females }\end{array}$ & $238(50.7)$ \\
\hline $\begin{array}{l}\text { Smoking habit: } \\
\text { smoker }\end{array}$ & $233(74.3)$ \\
never smoked & $77(25.7)$ \\
\hline $\begin{array}{l}\text { Histological type: } \\
\text { adenocarcinoma } \\
\text { squamous } \\
\text { other }\end{array}$ & $228(76.0)$ \\
\hline $\begin{array}{l}\text { Stage: } \\
\text { early (I; II; IIIA) } \\
\text { advanced (IIIB; IV) }\end{array}$ & $62(20.7)$ \\
\hline
\end{tabular}

as total final volume of $50 \mu \mathrm{L}$. The PCR method consisted of an initial denaturation step at $95{ }^{\circ} \mathrm{C}$ for $15 \mathrm{~min}$., followed by 42 cycles at $95{ }^{\circ} \mathrm{C}$ for 20 seconds, $54{ }^{\circ} \mathrm{C}$ for 30 seconds, $72{ }^{\circ} \mathrm{C}$ for 20 seconds, and a final extension step at $72{ }^{\circ} \mathrm{C}$ for $5 \mathrm{~min}$. The PCR products $(10 \mu \mathrm{L})$ were analyzed by electrophoresis on a $3.0 \%$ agarose gel to confirm successful amplification.

After validation of the PCR products on the gel, 40 $\mu \mathrm{L}$ of the products were bound to streptavidin Sepharose HP (GE Healthcare, Waukesha, WI, USA), purified, washed, and denatured using a $0.2 \mathrm{~mol} / \mathrm{L}$ sodium hydroxide solution, and washed again. Subsequently, $0.3 \mu \mathrm{mol} / \mathrm{L}$ pyrose-quencing primers were annealed to the purified single-stranded PCR products, and the pyrosequencing was performed on a PyroMark ID system (Qiagen GmbH), ac-

Table 2. Detailed clinicopathological characteristics of patients with EGFR and KRAS mutations.

\begin{tabular}{|c|c|c|c|c|c|c|c|}
\hline \multirow[t]{2}{*}{ Characteristics } & \multirow{2}{*}{$\begin{array}{l}\text { Patients } \\
(n=300)\end{array}$} & \multicolumn{2}{|c|}{$\begin{array}{c}\text { EGFR Mutations } \\
(32.33 \%)\end{array}$} & \multicolumn{2}{|c|}{$\begin{array}{c}\text { KRAS Mutations } \\
(25.0 \%) \\
\end{array}$} & \multicolumn{2}{|c|}{$\begin{array}{l}\text { EGFR and KRAS Mutations } \\
(6.6 \%)\end{array}$} \\
\hline & & {$[+](n=97)$} & {$[-](n=203)$} & {$[+](n=75)$} & {$[-](n=225)$} & {$[+](n=20)$} & {$[-](n=280)$} \\
\hline $\begin{array}{l}\text { Age: } \\
\quad \leq 62 \text { years } \\
\quad \geq 62 \text { years }\end{array}$ & $\begin{array}{l}148 \\
152\end{array}$ & $\begin{array}{l}50(32.9 \%) \\
47(31.8 \%)\end{array}$ & $\begin{array}{l}102(67.1 \%) \\
101(68.2 \%)\end{array}$ & $\begin{array}{l}32(21.1 \%) \\
43(29.1 \%)\end{array}$ & $\begin{array}{l}120(78.9 \%) \\
105(70.9 \%)\end{array}$ & $\begin{array}{r}7(4.6 \%) \\
13(8.8 \%)\end{array}$ & $\begin{array}{l}145(95.4 \%) \\
135(91.2 \%)\end{array}$ \\
\hline $\begin{array}{l}\text { Gender: } \\
\text { males } \\
\text { females }\end{array}$ & $\begin{array}{r}238 \\
62\end{array}$ & $\begin{array}{l}67(28.2 \%) \\
30(48.3 \%)^{\mathrm{a}}\end{array}$ & $\begin{array}{r}171(71.8 \%) \\
32(51.7 \%)\end{array}$ & $\begin{array}{l}63(26.5 \%) \\
12(19.4 \%)\end{array}$ & $\begin{array}{r}174(73.5 \%) \\
50(80.6 \%)\end{array}$ & $\begin{array}{r}16(6.7 \%) \\
4(6.5 \%)\end{array}$ & $\begin{array}{r}222(93.3 \%) \\
58(93.5 \%)\end{array}$ \\
\hline $\begin{array}{l}\text { Smoking habit: } \\
\text { smoker } \\
\text { never smoked }\end{array}$ & $\begin{array}{r}233 \\
77\end{array}$ & $\begin{array}{l}59(26.5 \%) \\
38(49.4 \%)^{\mathrm{a}}\end{array}$ & $\begin{array}{r}164(73.5 \%) \\
39(50.6 \%)\end{array}$ & $\begin{array}{l}58(26.0 \%) \\
17(22.0 \%)\end{array}$ & $\begin{array}{r}165(74.0 \%) \\
60(78.0 \%)\end{array}$ & $\begin{array}{c}11(4.9 \%) \\
9(11.6)\end{array}$ & $\begin{array}{r}212(88.4 \%) \\
68(88.4 \%)\end{array}$ \\
\hline $\begin{array}{l}\text { Histological type: } \\
\text { adenocarcinoma } \\
\text { squamous } \\
\text { other }\end{array}$ & $\begin{array}{r}228 \\
62 \\
10\end{array}$ & $\begin{array}{c}77(33.7 \%)^{\mathrm{a}} \\
13(21.0 \%) \\
7(70.0 \%)\end{array}$ & $\begin{array}{r}151(66.3 \%) \\
49(79.0 \%) \\
3(30.0 \%)\end{array}$ & $\begin{array}{r}55(24.1 \%) \\
18(29.0 \%) \\
2(20.0 \%)\end{array}$ & $\begin{array}{r}173(75.9 \%) \\
44(71.0 \%) \\
8(80.0 \%)\end{array}$ & $\begin{array}{l}16(7.0 \%) \\
2(3.2 \%) \\
2(20.0 \%)\end{array}$ & $\begin{array}{r}212(93.0 \%) \\
60(96.8 \%) \\
8(80.0 \%)\end{array}$ \\
\hline $\begin{array}{l}\text { Stage: } \\
\text { early (I; II; IIIA) } \\
\text { advanced (IIIB; IV) }\end{array}$ & $\begin{array}{r}70 \\
230\end{array}$ & $\begin{array}{l}18(25.7 \%) \\
79(34.3 \%)\end{array}$ & $\begin{array}{r}52(74.3 \%) \\
151(65.7 \%)\end{array}$ & $\begin{array}{l}16(22.8 \%) \\
59(25.6 \%)\end{array}$ & $\begin{array}{r}54(77.2 \%) \\
171(74.4 \%)\end{array}$ & $\begin{array}{r}2(2.8 \%) \\
18(7.8 \%)\end{array}$ & $\begin{array}{r}68(97.2 \%) \\
212(92.2 \%)\end{array}$ \\
\hline
\end{tabular}

\footnotetext{
${ }^{a}$ Found to be statistically significant.
} 
cording to the manufacturer's instructions and analyzed in the AQ mode of the PyroMark (Qiagen GmbH) software.

Statistical Analyses. All statistical analyses were done using the Statistical Package for the Social Sciences (SPSS) version 17.0 (SPSS ${ }^{\circledR}$ IBM Corporation, Armonk, NY, USA). For descriptive analyses, the $\chi^{2}$ and $t$-tests were performed. Progression-free survival and overall survival analyses, according to EGFR and KRAS mutations' status were done using the Kaplan Meier Method and estimating the survival difference with the use of long rank test. A value of $p<0.05$ was accepted to be statistically significant.

\section{RESULTS}

Patient Profiles. We conducted this study on paraffin-embedded tissues of 300 consecutive patients with NSCLC from January 2010 through January 2014. In the 300 patients with NSCLC, 230 (76.7\%) patients had ad- vanced disease, $62(20.7 \%)$ of these patients were female, $238(79.3 \%)$ were male. Histopathologically, there were 62 squamous and 228 adenocarcinoma NSCLC patients. The median age of the patients was 62 (range 37-82), 233 $(74.3 \%)$ had a history of smoking. The patient characteristics are summarized in Table 1.

EGFR Mutations Profiles. We detected EGFR mutations in 97 patients out of 300 patients, 30 of which were female and 67 were male patients. Histopathologically, 13 were squamous type 77 adenocarcinoma, while seven were in other subtypes. In terms of age, 50 patients were over 62 years old, 47 patients were less than 62 , and 59 of them are smokers. The EGFR mutations were found to be statistically significant in females, non smokers and adenocarcinoma patients. Eighteen patients were in early stages (I-IIIA), while 79 patients were in advanced stages (IIIB-IV), considering progression [9] (Table 2). We detected 53.5\% EGFR mutations in exon 19 [Table 3(A)].

Table 3. (A) Types of EGFR mutations in Turkish NSCLC patients.

\begin{tabular}{|c|c|c|c|c|}
\hline Mutation & Exon & Nucleotide Number & Amino Acid Changes & Mutation \\
\hline Point mutation & 18 & $2155(\mathrm{G}>\mathrm{T})$ & G719C & $1(0.8 \%)$ \\
\hline Point mutation & 18 & $2134(\mathrm{G}>\mathrm{A})$ & G719S & $3(2.5 \%)$ \\
\hline Point mutation & 18 & $2155(\mathrm{G}>\mathrm{A})$ & G719A & $9(7.6 \%)$ \\
\hline Deletion & 19 & 235-2249del (GGA ATT AAG AGA AGC) & delE746-A750 & $39(33.4 \%)$ \\
\hline $\mathrm{Del} / \mathrm{Ins}$ & 19 & 2235-2252del (GGA ATT AAG AGA AGC insCA) & L747-6751insP & $10(8.5 \%)$ \\
\hline Del/Ins & 19 & 2235-2252del (GGA ATT AAG AGA AGC insAAT) & delE746-T751insI & $5(4.2 \%)$ \\
\hline Del/Ins & 19 & 2235-2258del (GGA ATT AAG AGA AGC insAAT CCA) & delE746-A750insIP & $1(0.8 \%)$ \\
\hline Del/Ins & 19 & 2235-2249del (GGA ATT AAG AGA AGC insAGA) & delL747-P753insS & $3(2.5 \%)$ \\
\hline Del/Ins & 19 & 2235-2258del (GGA ATT AAG AGA AGC insAAT) & delE746-A750insI & $3(2.5 \%)$ \\
\hline Del/Ins & 19 & 2235-2258del (GGA ATT AAG AGA AGC insCCA) & delA746-A750insP & $1(0.8 \%)$ \\
\hline Del/Ins & 19 & 2235-2258del (GGA AAT AAG AGA AGC insCAA) & delL747-T751insQ & $1(0.8 \%)$ \\
\hline Point mutation & 20 & $2369(\mathrm{C}>\mathrm{T})$ & T790M & $3(2.5 \%)$ \\
\hline Point mutation & 21 & $2573(\mathrm{~T}>\mathrm{G})$ & L858R & $10(8.5 \%)$ \\
\hline Point mutation & 21 & $2582(\mathrm{~T}>\mathrm{A})$ & L861Q & $29(24.6 \%)$ \\
\hline
\end{tabular}

Del/Ins: deletions and insertions.

Table 3. (B) Types of KRAS mutations in Turkish NSCLC patients.

\begin{tabular}{|l|c|c|c|c|}
\hline Mutation Types & Codon & Nucleotide Number & Amino Acid Changes & Mutations \\
\hline Point mutation & 12 & $34(\mathrm{G}>\mathrm{A})$ & G12S & $10(12.7 \%)$ \\
\hline Point mutation & 12 & $34(\mathrm{G}>\mathrm{T})$ & G12C & $8(10.1 \%)$ \\
\hline Point mutation & 12 & $35(\mathrm{G}>\mathrm{A})$ & G12D & $6(6.7 \%)$ \\
\hline Point mutation & 12 & $35(\mathrm{G}>\mathrm{T})$ & G12V & $20(25.2 \%)$ \\
\hline Point mutation & 12 & $35(\mathrm{G}>\mathrm{A})$ & G12A & $1(1.3 \%)$ \\
\hline Point mutation & 13 & $37(\mathrm{G}>\mathrm{A})$ & G13D & $1(1.3 \%)$ \\
\hline Point mutation & 61 & $182(\mathrm{~A}>\mathrm{G})$ & Q61R & $18(22.8 \%)$ \\
\hline Point mutation & 61 & $183(\mathrm{~A}>\mathrm{C})$ & Q61H & $15(19.0 \%)$ \\
\hline
\end{tabular}


KRAS Mutation Profiles. Seventy-five of 300 patients have KRAS mutations, 12 of which were females, 63 were males. Histopathologically, 18 patients have squamous type NSCLC, while 55 have adenocarcinoma and two were in other subtypes. Thirty-two patients were older than 62 and 58 patients were smokers. Sixteen patients were in early stages and 59 patients were in advanced stages of cancer (Table 2). We found no statistically significant differences between KRAS mutations and age, gender, smoking, stage of the cancer.

We detected both EGFR-KRAS mutations in 20 patients, four females and 16 male patients. Histopathologically, two of them were squamous, 16 were adenocarcinoma and two were in other types. Two were in early stage, 18 were in advanced stages, 13 of them were older than 62. Eleven of them are smokers, while nine are not. Detailed information is given in Table 2.

Survival Rates of Patients with EGFR-KRAS Mutations. Fifty-nine patients who had either EGFR mutations or both EGFR and KRAS mutations, received

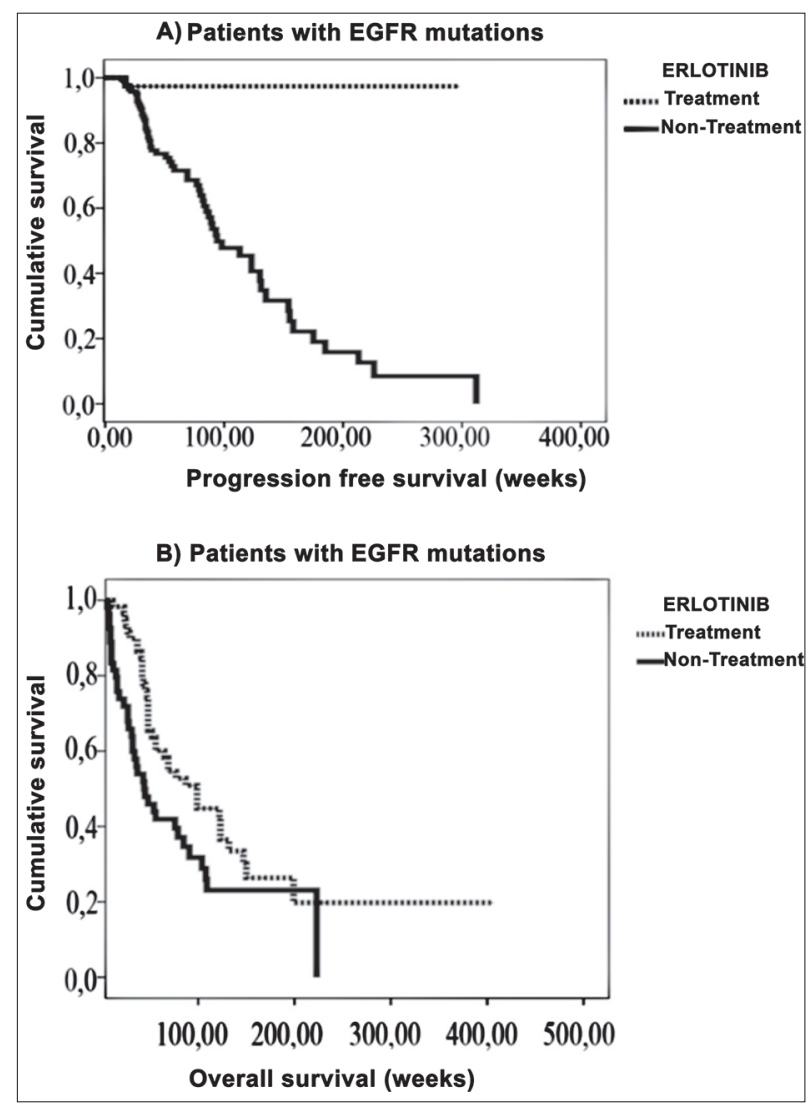

Figure 1. (A) The progression-free survival rate was statistically significantly higher in patients carrying EGFR mutations receiving EGFR-TKI therapy in comparison to patients having no such treatment. (B) The overall survival rate was statistically significantly higher in patients carrying EGFR mutations receiving EGFR-TKI therapy in comparison to patients having no such treatment. erlotinib therapy. We showed that survival rates of patients who received EGFR-TKI therapy was significantly higher than patients with EGFR mutations who did not receive erlotinib therapy [Figure 1(A) and 1(B)].

Twenty patients who have EGFR-KRAS mutations and were not treated with erlotinib, had the lowest survival rate (34 \pm 16 weeks) ( $p$ 0.0007) [Figure 2(B)]. Patients with both mutations and who received erlotinib therapy, had a survival rate of $98 \pm 16$ weeks [Figure 2(B)]. Patients who had only the EGFR mutation and were treated with erlotinib, had a survival rate of $161 \pm 30$ weeks [Figure 2(A)], and those who did not receive erlotinib therapy, had a survival rate of $90 \pm 13$ weeks [Figure 2(A)].

The overall survival rate patients treated with EGFRTKI without progression was also found to be significantly higher. Patients who were treated with EGFR-TKI: $288 \pm$ 11 and those who were not: $119 \pm 11$ weeks $(p 0.004)$ [Figure 1(A)]. Overall survival rates were $126 \pm 11$ in patients with EGFR mutations and $121 \pm 9$ weeks in other patients ( $p$ 0.266) [Figure 1(B)]. We observed, that patients who

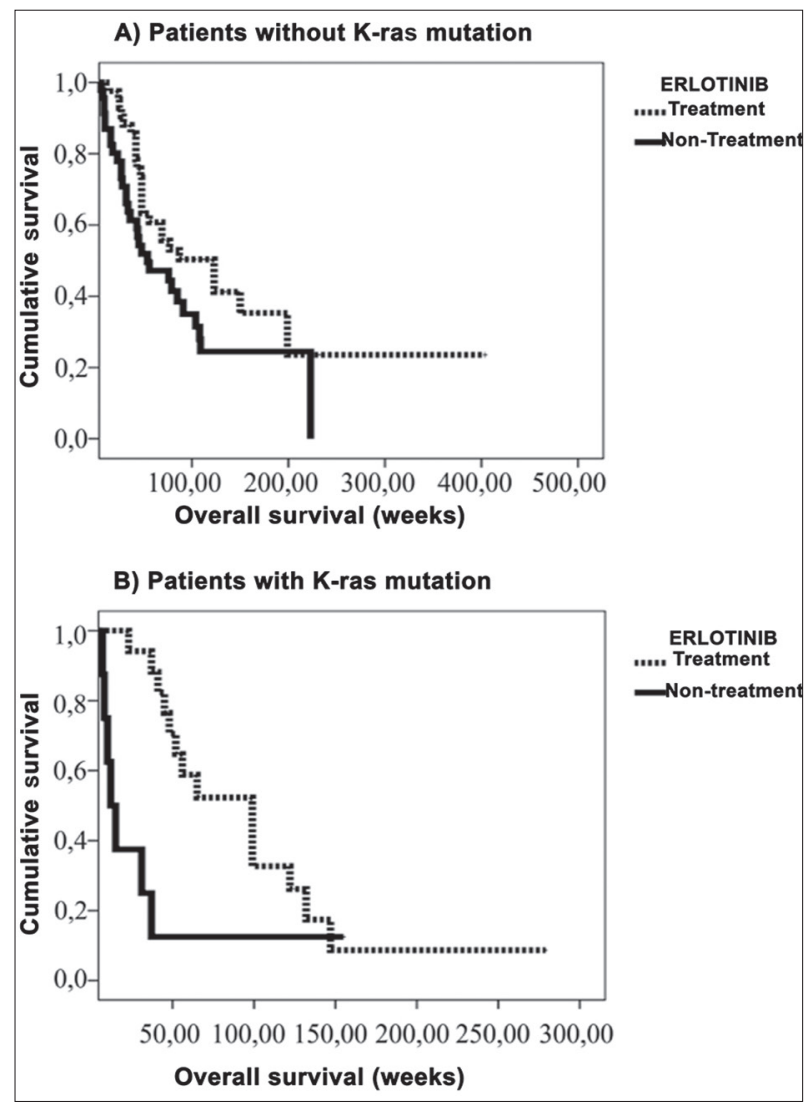

Figure 2. (A) The overall survival rate was statistically significantly higher in patients not carrying the KRAS mutations receiving EGFR-TKI therapy in comparison to patients having no such treatment. (B) The overall survival rate was statistically significantly higher in patients carrying the KRAS mutations receiving EGFR-TKI therapy in comparison to patients having no such treatment. 
have both EGFR and KRAS mutations, have the lowest overall survival rate and erlotinib therapy increased the survival rate in patients who have both mutations, while progression-free survival rates in patients treated with erlotinib were $32 \pm 5$ weeks, these rates were $33 \pm 3$ weeks in patients who were not treated with erlotinib ( $p$ 0.755). KRAS mutation $100 \pm 4$, without mutation $131 \pm 11$ weeks, $p 0.038$, and without a progression survival rate was not statistically significant (KRAS mutations $31 \pm 5$, without KRAS mutation $33 \pm 3$ weeks, $p$ 0.0807).

\section{DISCUSSION}

Non-small cell lung cancer has different subtypes, mainly adenocarcinoma, squamous and other subtypes. Of these, adenocarcinoma is seen more often in patients with NSCLC [10-13]. Previous studies that showed correlation can be found in literature regarding to the subtypes of NSCLC in the Turkish population $[9,14]$. In this study, we found $76.0 \%$ adenocarcinoma, $20.7 \%$ squamous, $3.3 \%$ other subtypes in 300 patients. The distribution of gender has been reported in the literature as: in East Asian communities $54.0-65.0 \%$ males, $35.0-46.0 \%$ females [10], in England 55.0\% males, $45.0 \%$ females [1], in America $58.0 \%$ males $42.0 \%$ females [1]. Two previous studies performed in the Turkish population, found $85.0 \%$ males and $15.0 \%$ females by Unal et al. [14], 75.0\% males and $25.0 \%$ females by Akca et al. [9]. Our results showed a similar gender distribution (Table 2). It has been reported that EGFR mutation rates range between 12.2 and 50.0\% in East Asia communities [10,15]. Recently, population studies have shown that European and American population have the lowest EGFR mutation rates, $6.0-16.0 \%$ and $15.0-20.0 \%$, respectively, in the world $[11,12]$.

We detected EGFR mutations in $33.0 \%$ of all 300 patients and $84.0 \%$ of EGFR mutation-carrying patients had adenocarcinoma. Previous studies also showed similar results, 66.0 and $81.0 \%$ EGFR mutation rates, respectively [9,14]. In our study, we found EGFR mutations in $48.0 \%$ female patients and in $28.0 \%$ male patients. This result is similar to previous reports that female patients who had NSCLC have higher EGFR mutations [10-13]. Regarding smoking habits, patients who do not smoke have more EGFR mutations [9-15]. In our study, we detected EGFR mutations in $49.0 \%$ of non smoking patients and in $28.0 \%$ of the smoking patients (Table 2). In the literature, EGFR mutations are seen more often in non smokers and female Asian patients [10]. Mutation rate also increases with advanced stages of NSCLC cancer (IIIB-IV) [10-13]. In our study, similar results were obtained in $18.6 \%$ early stage and $81.4 \%$ advanced stage in NSCLC patients with EGFR mutations.
The KRAS mutation rates in NSCLC patients were reported as 2.3-9.4\% in East Asian populations, 11.0$29.0 \%$ in North America, $12.0-31.0 \%$ in Europe, $25.0 \%$ in Mexico, $12.0 \%$ in Columbia and $12.0 \%$ in Peru [1012]. In our research, we found $20.8 \%$ patients had KRAS mutations (Table 2 ). We detected $65.0 \%$ KRAS mutations in codons 12 and 13 and $35.0 \%$ in codon 64 [Table 3(B)].

We also found that $6.6 \%$ of the patients carry both EGFR and KRAS mutations (Table 2). In the literature, this rate varied between 1.0 and $15.0 \%$ [10-12]. This is the first study in the Turkish population showing KRAS mutations and erlotinib therapy in NSCLC patients.

Fifty-nine of 97 patients with EGFR mutations were treated with EGFR-TKI agent (erlotinib). The average overall survival rates are $146 \pm 22$ weeks in EGFR-TKI treated patients and $84 \pm 12$ weeks in untreated patients. Similar results were published in the literature that erlotinib therapy increases overall survival [16] [Figure 1(B)].

The effect of EGFR-TKI treatment on a patient's survival without progression was found to be statistically significant. Erlotinib-treated patients' survival rate was 288 \pm 11 weeks and $119 \pm 11$ weeks in untreated patients. This result is in accordance with the literature [16]. EGFR-TKI treatment provided longer survival rates in patients carrying only EGFR mutations compared to the patients with both mutations [Figure 2(B)]. We report that the overall survival rates are $34 \pm 16$ weeks in patients with KRASEGFR mutations and $98 \pm 16$ weeks in EGFR mutations without KRAS mutations in erlotinib-treated patients. Thus, the longest overall survival rates were observed in patients with EGFR but without KRAS mutations, and the lowest overall survival rates were found in patient with EGFR and KRAS mutations in EGFR-TKI-treated patients. Therefore, this indicated that KRAS is a prognostic factor for NSCLC.

The mutations on the $K R A S$ gene constantly activate $\mathrm{K}$-ras protein, which in turn triggers cancer cell proliferation via the rapidly accelerated fibrosarcoma/mitogen-activated protein kinase kinase/extracellular signal regulated kinase (RAF/MEK/ERK) pathway, resulting in ERK transcriptional factor. Mutated K-ras also activates the phospo-inositide 3-kinase/phosphoinositide-dependent kinase/ protein kinase $\mathrm{B}$ (PI3K/PDK/AKT) and tuberous sclerosis complex 1/Ras homologue enriched in brain/mammalian target of rapamycin complex 1 (TSC-1/RHEB/mTORC1) pathways, which have a role in invasion and metastasis in cancer cells [17]. Our research showed that additional KRAS mutations are a strong parameter for prognosis. The KRAS mutations negatively affect survival rate with and without erlotinib therapy [18]. This result suggests that KRAS mutation analyses should be routinely performed together with EGFR mutation analyses in NSCLC patients. 
Declaration of Interest. The authors report no conflicts of interest. The authors alone are responsible for the content and writing of this article.

Funding. This study was partly supported by the Pamukkale University Scientific Foundation [\#2012SBE 002].

\section{REFERENCES}

1. Siegel R, DeSantis C, Virgo K, Stein K, Mariotto A, Smith T, et al. Cancer treatment and survivorship statistics, 2012. CA Cancer J Clin. 2012; 62(4): 220 241.

2. Ohashi R, Takahashi F, Cui R, Yoshioka M, Gu T, Sasaki S, et al. Interaction between CD44 and hyaluronate induces chemoresistance in non-small cell lung cancer. Cancer Lett. 2007; 252(2): 225-234.

3. Miller VA. EGFR mutations and EGFR tyrosine kinase inhibition in non-small cell lung cancer. Semin Oncol Nurs. 2008; 24(1): 27-33.

4. Soria JC, Mok TS, Cappuzzo F, Jänne PA. EGFRmutated oncogene-addicted non-small cell lung cancer: Current trends and future prospects. Cancer Treat Rev. 2012; 38(5): 416-430.

5. Cox DA, Der JC. Ras history: Small GTPases. 2010; 1(1): 2-27.

6. Adjei A. Blocking oncogenic ras signaling for cancer therapy. J Natl Cancer Inst. 2001; 93(14): 1062-1074.

7. Monticone M, Biollo E, Maffei M, Donadini A, Romeo F, Storlazzi CT, et al. Gene expression deregulation by KRAS G12D and G12V in a BRAF V600E context. Mol Cancer. 2008; 7(1): 92-104.

8. Wicki A, Herrmann R, Christofori G. Kras in metastatic colorectal cancer. Swiss Med Wkly. 2010; 140(1): 13112-13119.

9. Akca H, Demiray A, Yaren A, Bir F, Koseler A, Iwakawa R, et al. Utility of serum DNA and pyrosequencing for the detection of EGFR mutations in nonsmall cell lung cancer. Cancer Genet. 2013; 206(6): 73-80.

10. Chang ET, Shema SJ, Wakelee HA, Clarke CA, Gomez SL. Uncovering disparities in survival after nonsmall cell lung cancer among Asian/Pacific Islander ethnic populations in California. Cancer Epidemiol Biomarkers Prev. 2009; 18(8): 2248-2255.
11. Arrieta O, Cardona AF, Martín C, López L, Rodríguez L, Bramuglia G. Updated frequency of EGFR and KRAS mutations in non-small cell lung cancer (NSCLC) in Latin America: The Latin-American Consortium for the Investigation of Lung Cancer (CLICaP). J Thorac Oncol. 2015; 10(5): 838-843.

12. Smits AJJ, Kummer JA, Hinrichs JWJ, Herder GJM, Scheidel-Jacobse KC, Jiwa NM. EGFR and KRAS mutations in lung carcinomas in the Dutch population: increased EGFR mutation frequency in malignant pleural effusion of lung adenocarcinoma. Cell Oncol. 2012; 35(3): 189-196.

13. Ciećkiewicz S, Olszewski WT, Tysarowski A, Kowalski DM, Głogowski M, Krzakowski M, et al. EGFR mutation testing on cytological and histological samples in non-small cell lung cancer: A Polish, single institution study and systematic review of European incidence. Int J Clin Exp Pathol. 2013; 6(12): 28002812.

14. Unal OU, Oztop I, Calibasi G, Baskin Y, Koca D, Demir N. Relationship between epidermal growth factor receptor gene mutations and clinicopathological features in patients with non-small cell lung cancer in Western Turkey. Asian Pacific J Cancer Prev. 2013; 14(6): 3705-3709.

15. Yatabe Y, Kerr KM, Utomo A, Rajadurai P, Tran VK, $\mathrm{Du} \mathrm{X}$, et al. EGFR mutation testing practices within the Asia Pacific Region. J Thorac Oncol. 2015; 10(3): 438-445.

16. Melosky B. Review of EGFR TKIs in metastatic NSCLC, including ongoing trials. Front Oncol. 2014; 4: 244.

17. Shigematsu H, Lin L, Takahashi T, Nomura M, Suzuki M, Wistuba II, et al. Clinical and biological features associated with epidermal growth factor receptor gene mutations in lung cancers. J Natl Cancer Inst. 2005; 97(5): 339-346.

18. Eberhard DA, Johnson BE, Amler LC, Goddard $\mathrm{AD}$, Heldens SL, Herbst RS, et al. Mutations in the epidermal growth factor receptor and in KRAS are predictive and prognostic indicators in patients with non-small-cell lung cancer treated with chemotherapy alone and in combination with erlotinib. J Clin Oncol. 2005; 23(25): 5900-5909. 